\title{
SICODYN international benchmark on dynamic analysis of structure assemblies: variability and numerical-experimental correlation on an industrial pump (part 2)
}

\author{
Sylvie Audeberta ${ }^{a}$, Alexeï Mikchevitch And Irmela Zentner \\ Electricité de France Research \& Development, EDF Lab Clamart, Acoustics and Mechanical Analyses Department, \\ 1 avenue du Général de Gaulle, 92141 Clamart Cedex, France
}

Received 23 April 2013, Accepted 27 January 2014

\begin{abstract}
An international benchmark has been organized by EDF R\&D during 2008-2010, gathering 11 partners. Its main objective is to quantify the confidence in numerical models. The built-up dynamical system considered is a pump actually in service in power plants, considered in its work environment. Blind eigenfrequency numerical values relative to the pump assembly fixed in concrete present a larger variability than the $5 \%$ rough variability concerning the separate parts, essentially due to the modeling of the boundary conditions and interfaces at macro level. For the nine first eigenmodes considered, experimental-numerical correlation shows a frequency error less than $15 \%$ for the free sub-structures and nearly $30 \%$ for the free five-component system. Though the first overall modes are correctly identified, the frequency error is significantly larger for the clamped pump assembly, with however MAC coefficients higher than 0.9 for two modes; but the frequency error can be reduced to less than $9 \%$ for the four first modes after updating procedure. A lesson to draw is that measurement information is needed to improve the quality of theoretical built-up structure. After this benchmark, a more ambitious research program will follow as a FUI project, gathering the observation of numerical and experimental variabilities, updating model improvement and numerical quantification of the total uncertainty.
\end{abstract}

Key words: Benchmark / built-up structure / modal analysis / numerical-experimental correlation / numerical variability

\section{Introduction}

A main objective of industrial companies is to quantify the confidence they have in numerical models used either in design purpose or in expertise purpose. The systems of interest include proposed or existing systems that operate at design conditions, at off-design conditions and at failure-mode conditions that apply in accident scenarios. In particular, the dynamical behaviour of engineered systems that equipped power plants must be confidently predicted. The numerical models built to do so in a design purpose must be able to represent the characteristics of the structure itself, its coupling with its environment, the usually unknown excitations and the corresponding error sources and uncertainties; in an expertise purpose, where measurements can be carried out on the existing structure, the numerical models are generally generic and must be able to reproduce the behaviour of the whole family of nominally-identical structures: their accuracy can

\footnotetext{
${ }^{a}$ Corresponding author: sylvie.audebert@edf.fr
}

be improved using measurement results, so that they can be used for instance to predict the effects of a structural modification.

SICODYN 2008-2010 benchmark purpose is not, as many benchmarks do [1-6], to verify, nor validate nor calibrate a structure dynamic software, but clearly to quantify, from an industrial point of view, that is in the real conditions of an engineering study, the variability of computational blind results, the discrepancy between numerical and measured results, and the improvement of this discrepancy using measurement information. However the general Verification and Validation (V\&V) comprehensive methodology based on benchmarks described in references [1-6] can be kept in mind and successfully applied within the purpose of the observation of the numerical variability: a step-by-step procedure from the free-free sub-structure to the assembly with complex boundary conditions is so here applied. Organized by EDF R\&D and gathering 11 international partners, SICODYN benchmark allowed the comparison of 


\section{Nomenclature}

\begin{tabular}{|ll|}
\hline CAD & Computer-Aided Design \\
$E$ & Coefficient of variation \\
EDF R\&D & Mathematical expectation \\
$\mathbf{f}$ & Electricité de France Research \& Development \\
$\hat{\mathbf{f}}=\left(\hat{f}_{1}, \ldots, \hat{f}_{8}\right)$ & Function relating $\mathbf{X}$ input and $\mathbf{Y}$ output $(\mathbf{Y}=\mathbf{f}(\mathbf{X}))$ \\
$F R E Q$ & Meta-model function of $\mathbf{f}$ \\
$\mathrm{FUI}$ & Eigenfrequency $(\mathrm{Hz})$ \\
$k_{x i}$ & Fonds Unifié Interministériel \\
$k_{y i}$ & Horizontal stiffness of joint $i$ in direction $X\left(\mathrm{~N}^{-1}\right)$ \\
$M$ & Horizontal stiffness of joint $i$ in direction $Y\left(\mathrm{~N}^{-1}\right)$ \\
$M A C$ & Mean gap value \\
$N_{\mathrm{S}}$ & Modal Assurance Criterion \\
$R$ & Sample size \\
$S_{i}$ & Correlation coefficient \\
$S t d$ & 1st order Sobol's indice relative to $X_{i}$ input \\
$V A R$ & Standard deviation \\
$w_{i}$ & Variance \\
$\bar{x}$ & Weight \\
$\mathbf{x}_{\mathrm{opt}}$ & Mean value \\
$\mathbf{X}=\left(X_{1}, \ldots, X_{12}\right)$ & Optimal parameter value \\
$\mathbf{X}=\left\{\mathbf{X}^{1}, \mathbf{X}^{2}, \ldots, \mathbf{X}^{N s}\right\}$ & Vector of input parameters \\
$\mathbf{Y}=\left(Y_{1}, \ldots, Y_{8}\right)$ & Input sample \\
$Y_{1}, \ldots, Y_{4}$ & Vector of output parameters \\
$Y_{5}, \ldots, Y_{8}$ & Eigenfrequencies relative to the four first modes $(\mathrm{Hz})$ \\
$\hat{\mathbf{Y}}=\left(\hat{Y}_{1}, \ldots, \hat{Y}_{8}\right)$ & Numerical/experimental $M A C$ numbers relative to the four first modes \\
& Vector of meta-model output parameters \\
\hline
\end{tabular}

dynamical modal simulation results obtained by the partners and the confrontation with experimental measurements obtained by EDF R\&D. The industrial point of view is taken into account by the fact that (1) here input benchmark data are not equally determined for all the partners, in order to consider their inherent uncertainty (data provided by EDF are but paper plans of the assembled pump and its parts, and CAD models of the eight main pump components); (2) the chosen demonstrator is an industrial structure in use in EDF thermal units: it is well-representative of modeling complexity and is characterized by not well-known parameters (the fluid excitation for instance); contrary to the methodology generally followed within benchmarks, it is not a structure specifically dedicated to the benchmark purpose as in the GARTEUR benchmark study [7]; (3) reference experimental data have been obtained in situ, as in benchmarks studies concerned with modal characteristics of a historical masonry monument [8] or a foundation structure of a turbine generator system [9]. This original benchmark approach, described in a first paper [10], is well adapted to the questions an industrial company must answer and critical decisions it must take: what is the confidence level of the simulationbased predictions provided by design offices? Are they sufficiently robust to uncertainties to authorize the cancellation or the decrease of experimental tests which characterize the dynamical behavior of the structure? What experimental tests are minimally needed to improve the numerical model and use it with confidence?

These questions are all the more pertinent since the structures concerned are built-up structures, which are joined assemblies of separate components. It is well known that the complex behaviour of connecting elements plays an important role in the overall dynamic characteristics, such as natural frequencies, mode shapes, and non-linear response characteristics to external excitations. As a consequence, the quality of theoretical built-up structure models lags far behind the quality achieved in conventional structure components, due to the lack of appropriate models of the interfaces and joints, easily usable in case of real industrial degree of complexity: the benchmark results hereafter presented will comparatively give quantitative orders of magnitude relative to the numerical variability of such models.

The representation of such predictive numerical models can however be largely improved using experimental information that is eigenfrequency and mode shape values. Input parameters such as material characteristics can first be tuned to compensate for the components which have not been modeled and to lessen the impact of not well known values; joint equivalent stiffnesses at interfaces or boundaries can then be adjusted so that the discrepancy between predicted and measured modal results is minimized. 


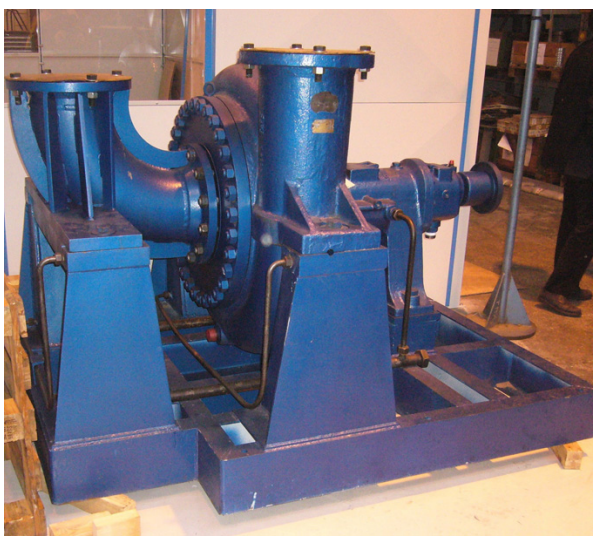

(a)

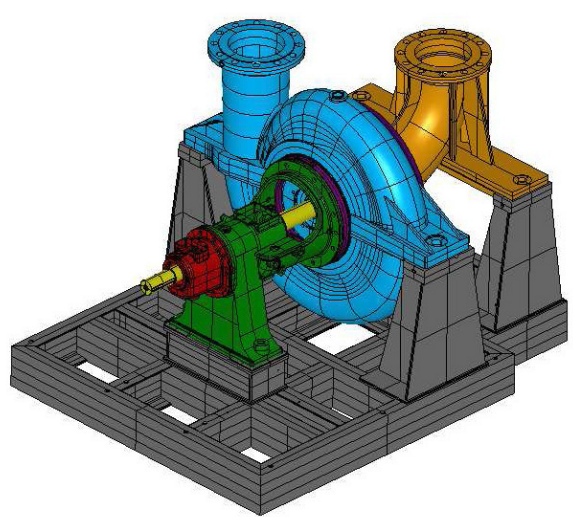

(b)

Fig. 1. (a) The one-stage booster pump and (b) its CAD model of the eight main component assembly.

Improvement of purely predictive models can also be obtained using detailed representations of the bolted joints, as proposed in literature [11-13], which take into account contact and friction phenomenon: implementation of a reduced-order description of the micro-slip that occurs at the interface between components is so described in reference [13]. But time to elaborate the numerical model and computational effort itself can grow unacceptably large for our numerous degree-of-freedom models of interest. So this way is not presently retained as the purpose of the work presented.

In this paper, after a presentation of the reference experimental data collected, the observed variability of blind modal simulated predictions is underlined and the numerical-experimental correlation performed: following a hierarchical process which considers more complexity in assembly and boundary condition, results concern separate free pump components, an intermediate free fivecomponent system and the pump assembly with frame clamped in concrete. Two-step updating results are then shown, relatively to the pump assembly model.

Quantitative results obtained in SICODYN benchmark lead the opportunity to build a more ambitious research program whose objectives are the quantification and the improvement of the credibility of numerical models in structure dynamics thanks numerical-experimental correlation and estimation of uncertainties. Based on the same industrial structure demonstrator but in complex environment, attempt will be made to provide userfriendly methods to a priori estimate the confidence level of simulation-based predictions. The scientific organisation of this FUI project is presented.

\section{Reference data}

The chosen equipment is a pump used in EDF thermal units (Fig. 1). It is a one-stage booster pump, composed of a diffuser and a volute, with axial suction and vertical delivery (body with volute called "snail"), mounted on a metallic frame. It was designed forty years ago by Sulzer Pumps. It is a bolted assembly of eight main components, as it is shown in Figure 2.

Five experimental modal analysis campaigns have been performed, increasing complexity in the structure and on its environment. The configurations of interest were the following:

- shaft \& impeller system, bearing support and pump casing in free-free conditions;

- shaft \& bearing support \& cooling flange \& pump casing \& bearing casing system in free - free conditions;

- assembled pump in free-free conditions;

- assembled non rotating non connected pump, fixed in concrete;

- assembled non rotating pump connected to pipes, and fixed in concrete.

For all tests performed, the sensitivity of force sensors and accelerometers used are respectively $0.23 \times 10^{-3}$ V.N ${ }^{-1}$ and $100 \times 10^{-3} \mathrm{~V} \cdot \mathrm{g}^{-1}$.

\subsection{Example of experimental results on a separate component: the pump casing}

Experimental modal results obtained on the free-free pump casing are presented on Table 1. The free-free boundary condition was obtained using a flexible sling. The excitation was performed using the roving hammer technique on two distinct points located on the center belt and on the delivery part (cf. Tab. 1). 25 measurement points instrumented with accelerometers in three directions constitute the experimental mesh. The sampling frequency is $4096 \mathrm{~Hz}$. The ten first identified eigenfrequencies are listed.

In order to quantify the experimental variability relative to different specimens of the same structure, a comparison has been made between two measurements on the pump casing carried out on two nominally identical structures. Figure 3 presents the frequency gap 

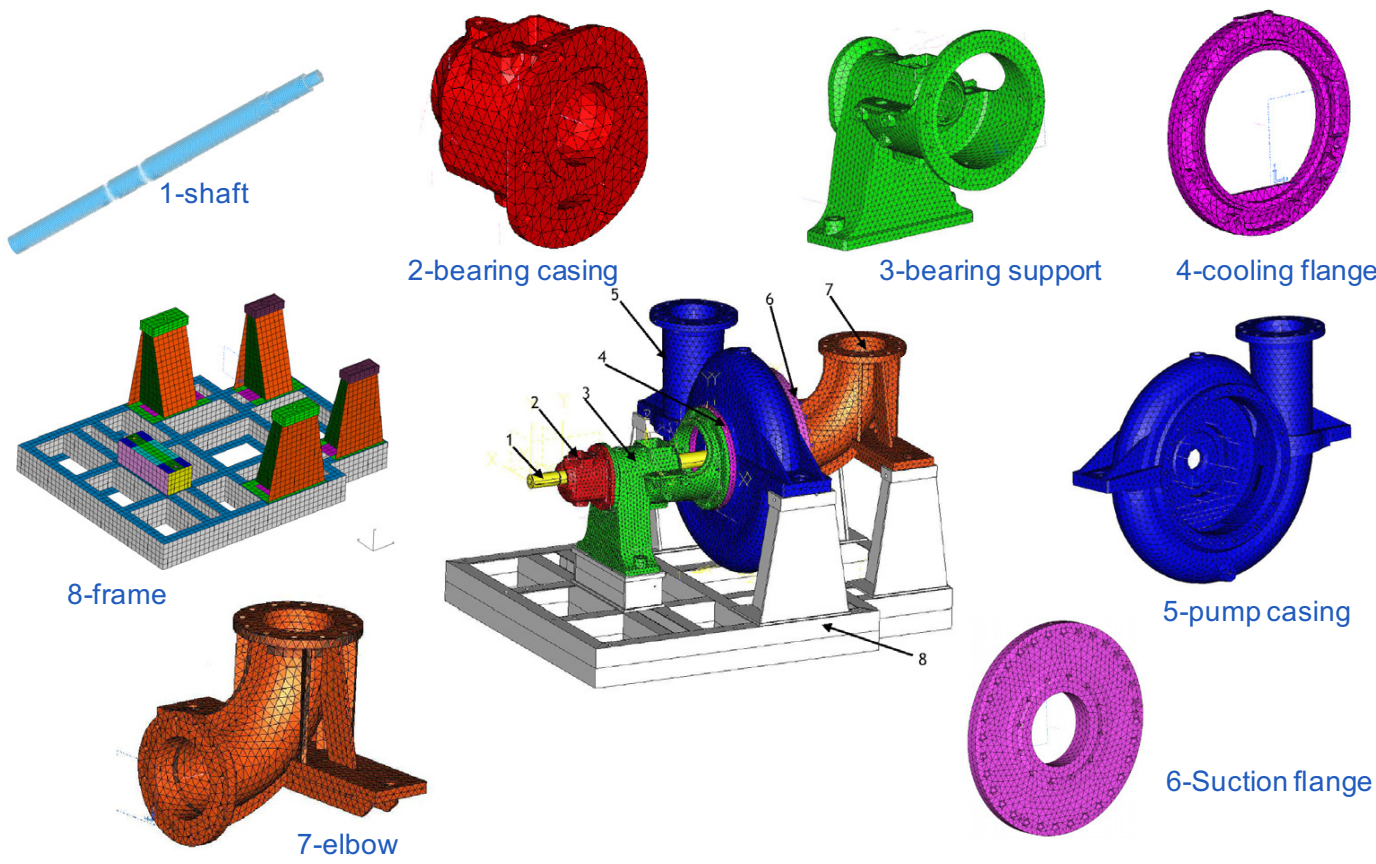

6-Suction flange

Fig. 2. The CAD models of the eight main pump components.

Table 1. Pump casing experimental results.

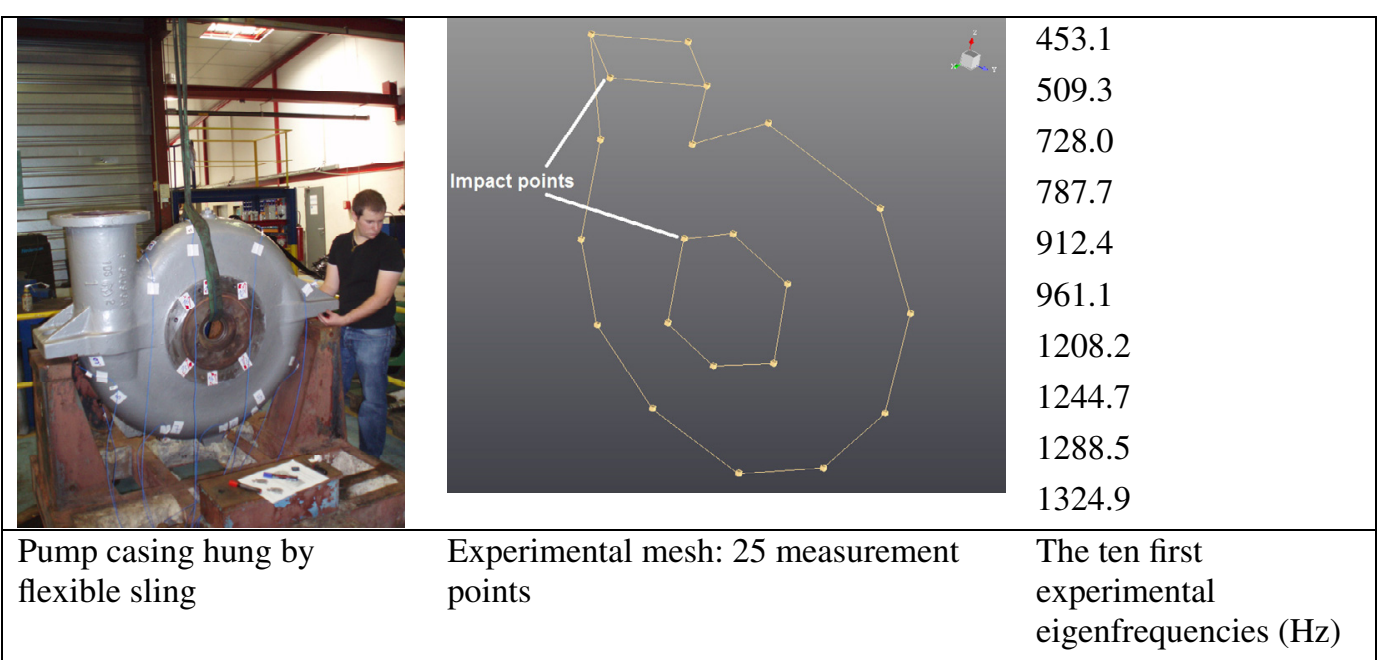

obtained: it is $3 \%$ at the maximum for the six first eigenmodes. In addition, quantitative natural frequency variability on another structure (a brake component) can be found in reference [14].

\subsection{An intermediate five-component system}

In order to validate the representation of the connections between pump components, an experimental modal analysis of a five-component system has been performed. A general view of the bolted system, the corresponding experimental mesh and the ten first eigenfrequencies are presented in Table 2.

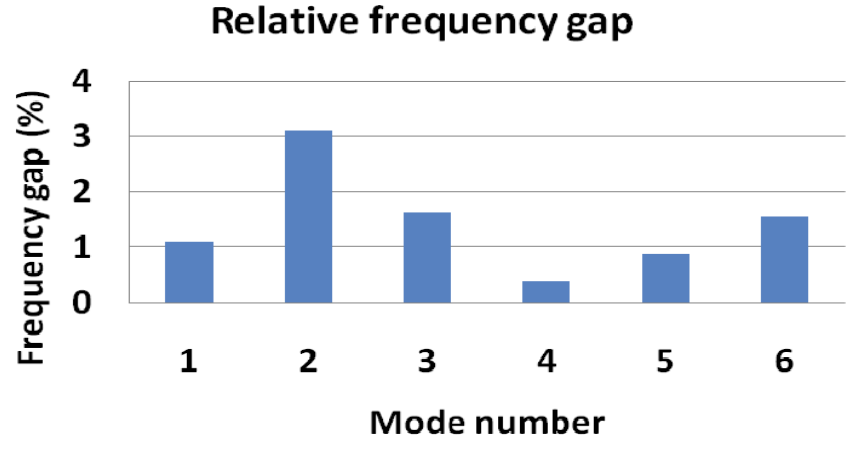

Fig. 3. Free-free pump casing: experimental frequency gap relative to nominally identical structures. 
Table 2. Five pump component system.

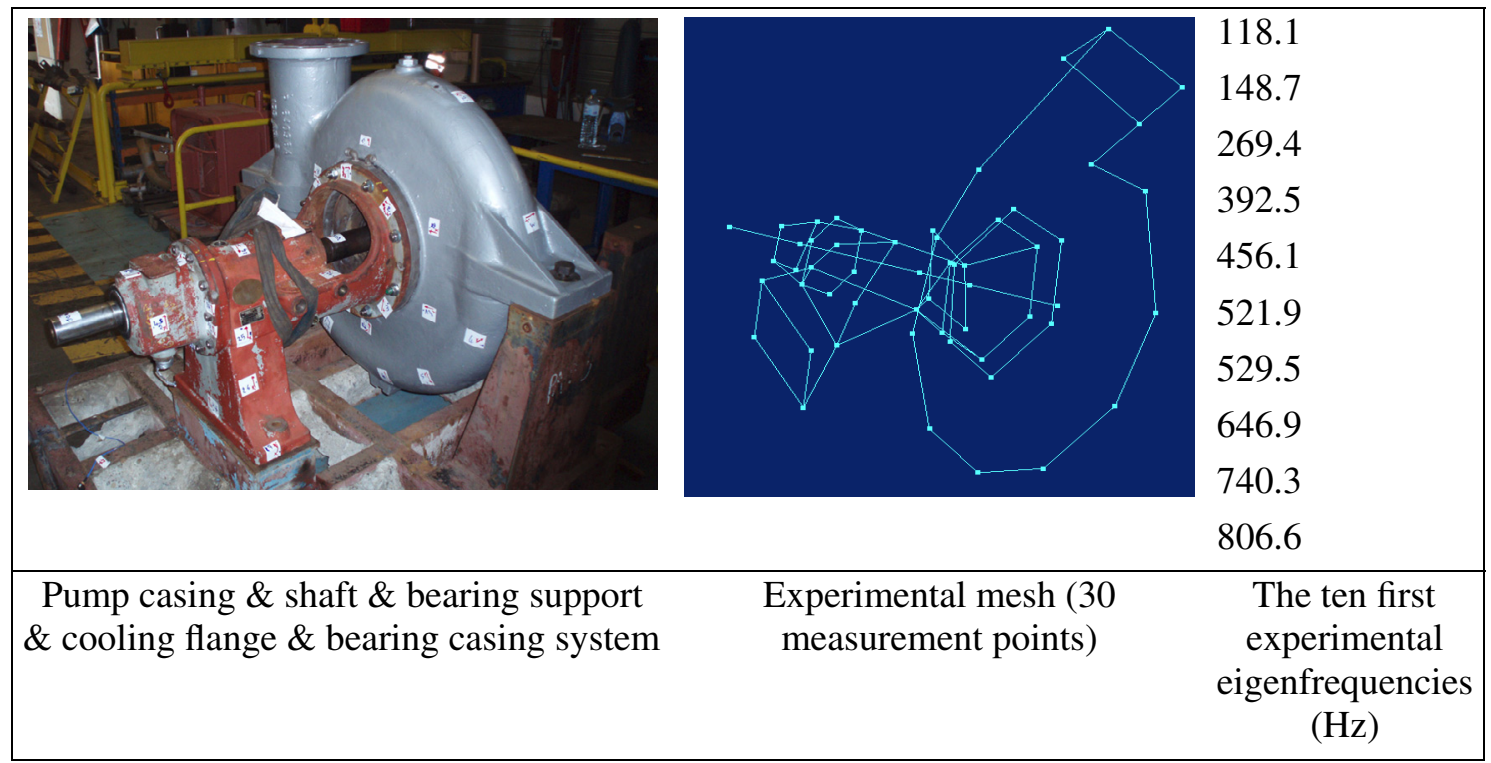

Table 3. Measured data on the pump assembly fixed in concrete.

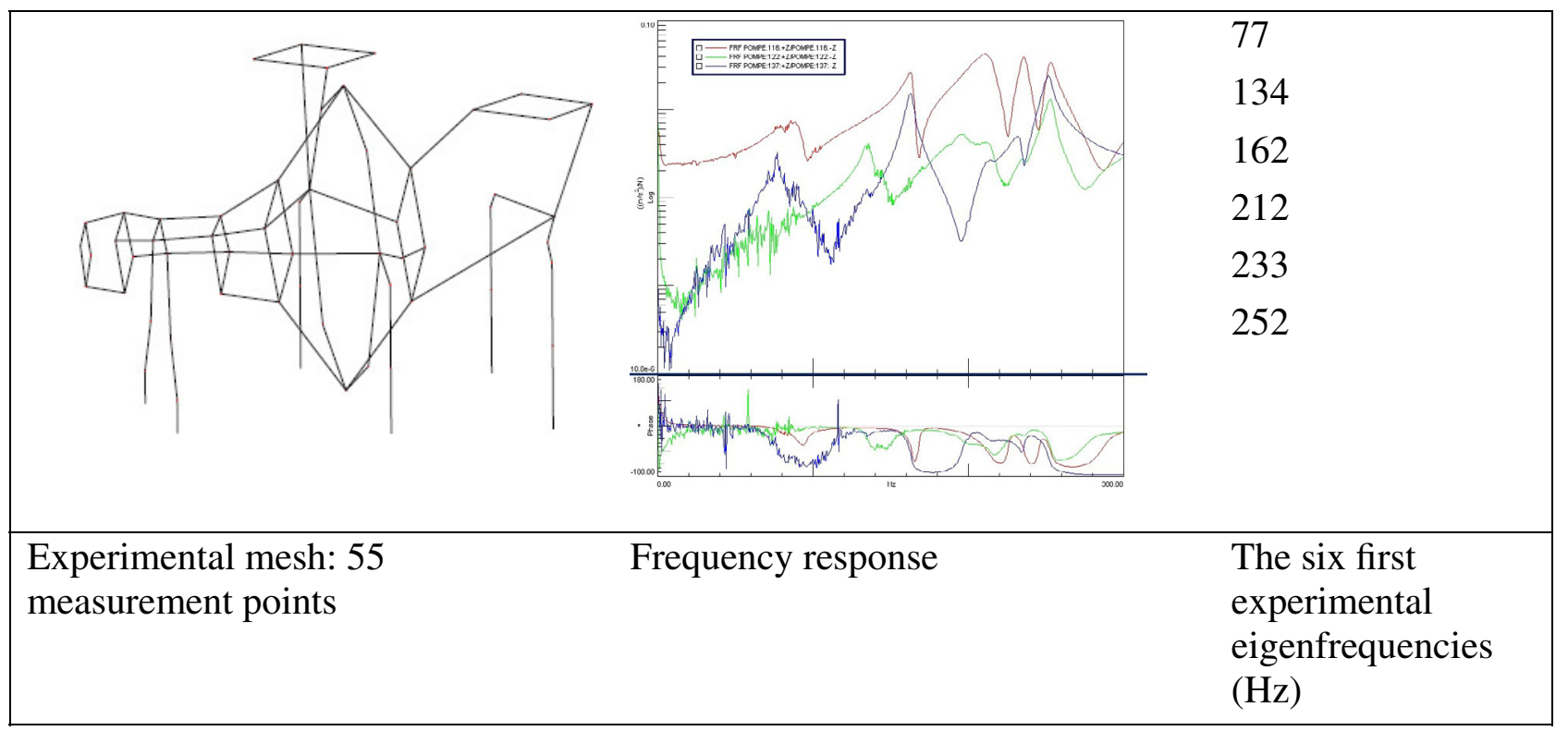

\subsection{Clamped non connected pump assembly}

The experimental mesh relative to the assembled pump contains 55 measurements points (Tab. 3). The pump was excited using an impact hammer in 3 distinct points: a point located at the bearing casing, orthoradial horizontal direction, a point at the bearing support in vertical direction and a point on one of the poles which supports the pump casing. An example of frequency response is given in Table 3. Five mean operations have been carried out for each frequency response. The sampling frequency is $4096 \mathrm{~Hz}$.

\section{Comparative blind modal results}

\subsection{Observed numerical variability}

\subsubsection{Separate pump components}

Table 4 shows the ten first eigenfrequency values relative to the eight free pump components obtained by the partners.

In addition, Figure 4 shows the mean frequency gap values roughly considered (i.e. with all sources of discrepancies) relative to blind results obtained on the eight main pump components. The $M$ mean gap value is obtained 
Table 4. The ten first eigenfrequencies computed by the partners for the eight main pump components.
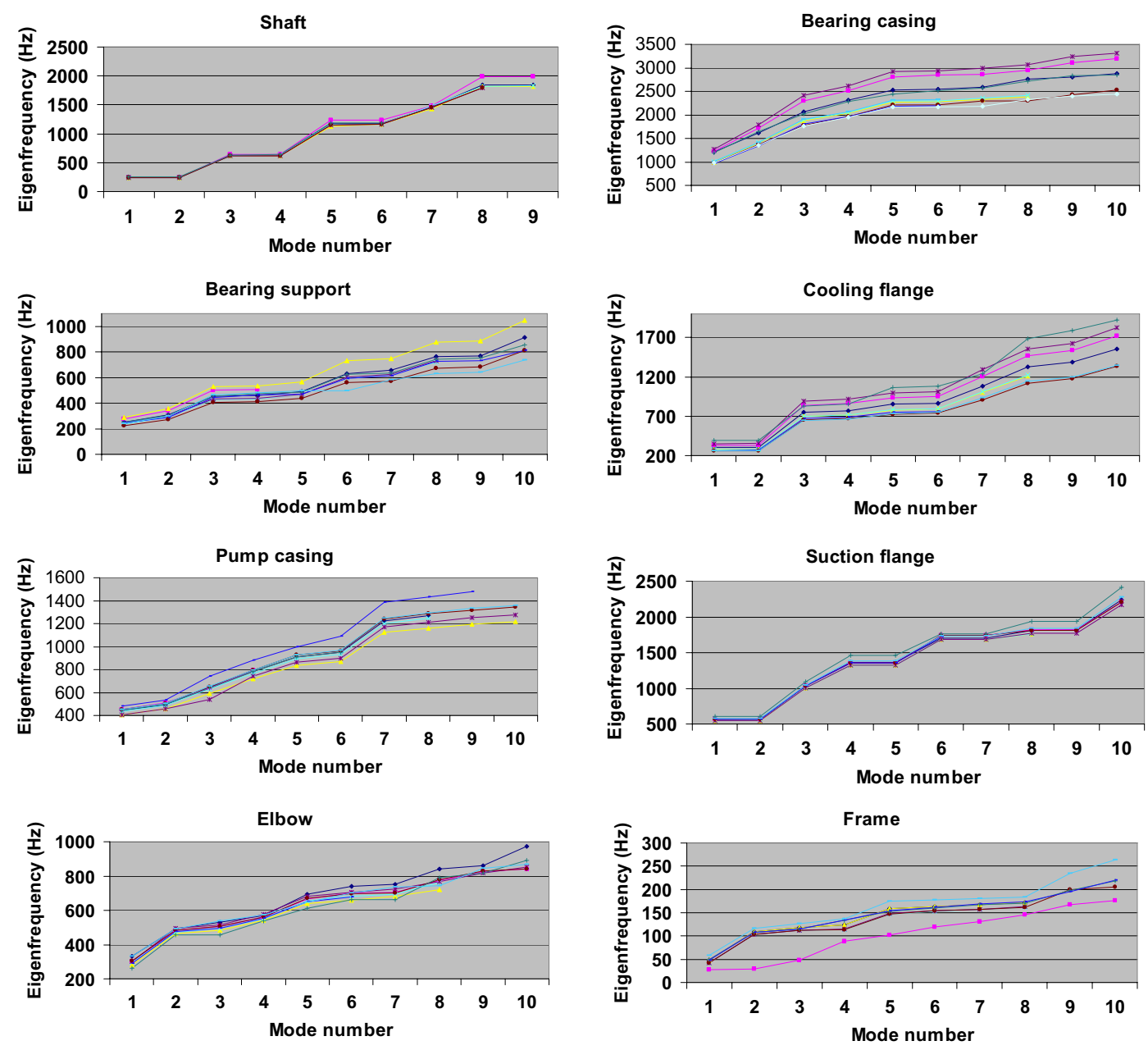

using the relationship (1):

$$
M=\frac{1}{n} \sum_{i=1}^{n}\left|x_{i}-\bar{x}\right|
$$

where $n$ denotes the number of results, $x_{i}$ and $\bar{x}$ the mean value defined by (2):

$$
\bar{x}=\frac{1}{n} \sum_{i=1}^{n} x_{i}
$$

The comparison of numerical modal analyses of free-free separate components shows discrepancy values that are not so negligible if we consider the fact that there is no boundary condition variability. The minimal discrepancies on eigenfrequency values concern the elbow and the suction flange. As expected, the variability associated to eigenfrequency values can be in a large part related to the variability associated with the material properties considered by the participants: the steel pump components (shaft, pump casing, suction flange, elbow, frame) present a mean gap around $5 \%$ (to be related with $2 \%$ variability on Young's modulus), whereas the cast iron components

(bearing support, bearing casing, cooling flange) show a higher mean gap around $11 \%$ (to be related with $20 \%$ variability on Young's modulus). This high variability on cast iron material property values corresponds to different possible shade cast. If we consider the mean frequency gap after elimination of material characteristic discrepancies, it is, as expected, a bit lower when the material characteristics values are the same $(5.5 \%$ for rough results to $4.4 \%$ with the same characteristics). Nevertheless, the bearing support and the cooling flange are still the components that present the higher frequency gap (10\% maximum).

The variability is also related to the quality of the geometrical support: simplifications of the geometry in order to reduce the mesh size could have been performed. And attention must be given in the mesh quality even if the mesh convergence is achieved: for instance an insufficient number of elements in the component depth could make the structure too stiff than it should be.

The frame is the pump component with the lowest eigenfrequencies, even if its lower part is in a concrete slab: it will certainly be more influent on the dynamic behaviour of the assembled structure than the other components. The bearing casing is, on the opposite, the stiffest 
Free pump components: global results

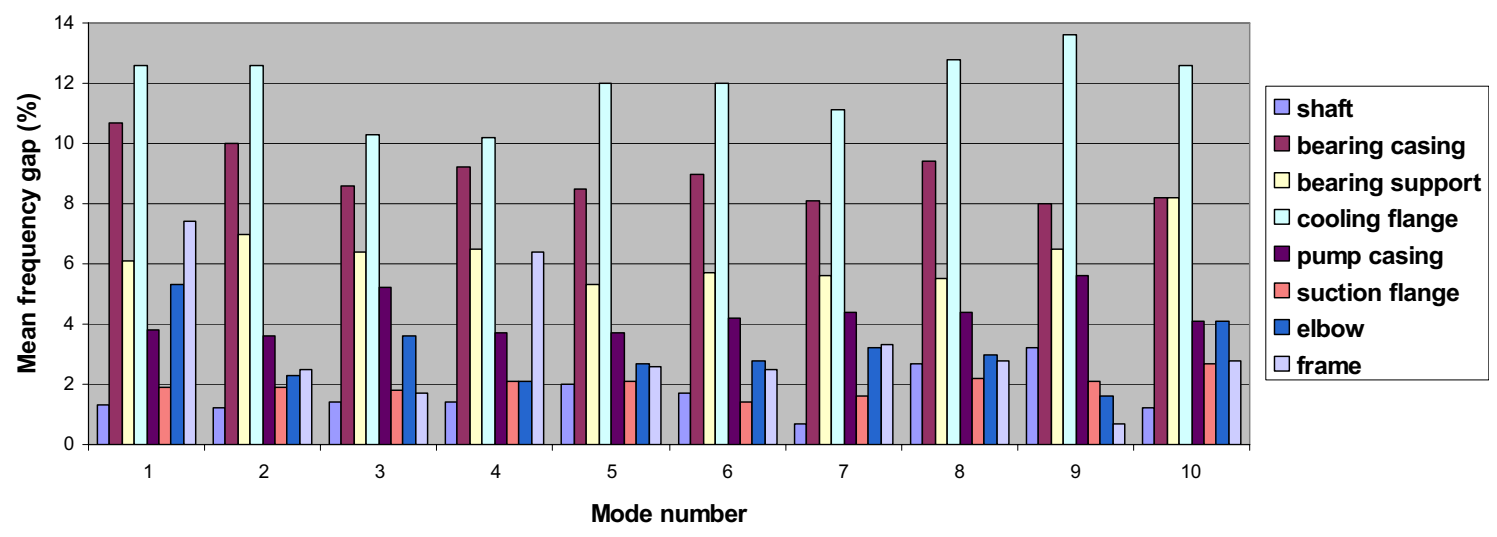

Fig. 4. Mean frequency gap relative to the free-free pump components.

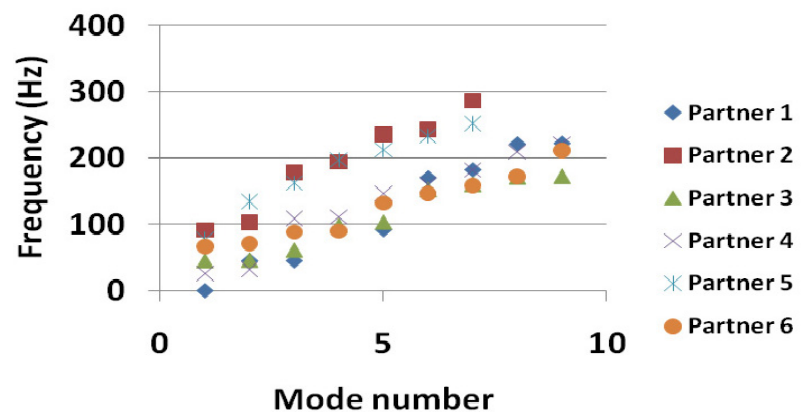

Fig. 5. Blind eigenfrequency simulation results relative to non rotating pump assembly fixed in concrete.

component, for which an experimental modal analysis will not be necessary.

\subsubsection{Non rotating pump assembly fixed in concrete}

The pump components have been assembled by the partners generally using either kinematics relationships or sticking the surfaces concerned. The boundary condition relative to the frame completely fixed in concrete has been taken into account by clamping all or parts of the nodes that belong to the frame. Rough results without mode paring attempt are illustrated as a point cloud relative to eigenfrequency results in Figure 5: as expected, one can observe a much greater variability than for separate pump components. A thorougher blind simulation result comparison, using mode paring, is included in the numerical-experimental correlation study in Section 3.2.3.

\subsection{Numerical-experimental correlation}

Numerical-experimental correlation has been performed relative to separate pump components (in case of available measurement data), to an intermediate fivecomponent system and to the pump assembly clamped in concrete.

\subsubsection{Separate pump components}

A numerical-experimental correlation could be performed on the shaft \& impeller system, the bearing support and the pump casing. The numerical-experimental correlation is illustrated in Figure 6, for each eigenmode, by vertical lines representing the interval constituted by the minimum and maximal numerical eigenfrequency values obtained by the participants and horizontal lines corresponding to experimental eigenfrequency values: the crossing of a horizontal line with a vertical line means that the experimental eigenfrequency is situated within the numerical interval.

Concerning the shaft \& impeller system, the numerical modal results are not exactly blind because, due to the fact that the impeller CAD model is not available, equivalent mass and inertia values have been determined using the experimental modal data. Comparing the interval constituted by the minimum and maximal eigenfrequency values obtained by four participants to the measured corresponding values (Fig. 6a), we can notice that every measured frequency is contained within the interval. The prediction accuracy on eigenfrequency values is less than $35 \%$ for the majority of considered modes; it is rather not very good for the double flexural modes 5 and 6 , but excellent on double flexural modes 1 and 2 and torsional mode 7 .

Concerning the bearing support, a first rough comparison between numerical and experimental eigenfrequency values suggests that the third experimental mode cannot be identified. Figure $6 \mathrm{~b}$ shows the blind comparison between the set of numerical modal results and the experimental modal data relative to the ten first eigenmodes, considering the shift due to this missing experimental mode. Comparing the interval constituted by the minimum and maximal eigenfrequency values obtained by eight participants to the measured corresponding values (Fig. 6), we can notice that every measured frequency is contained within the interval. The prediction accuracy on eigenfrequency values is less than $15 \%$ for the majority of considered modes. 


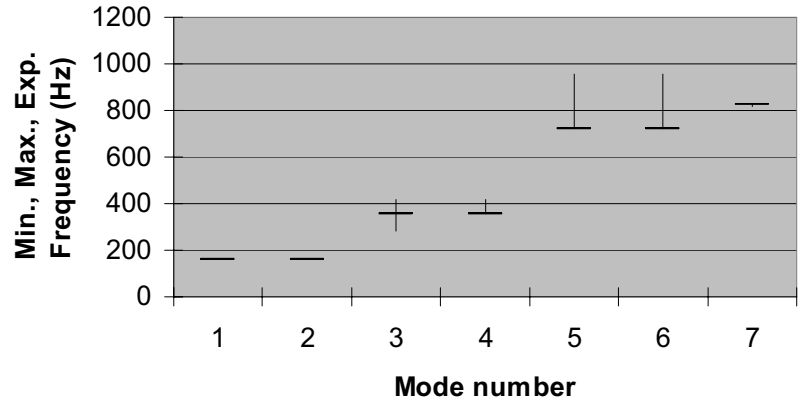

a) shaft \& impeller system

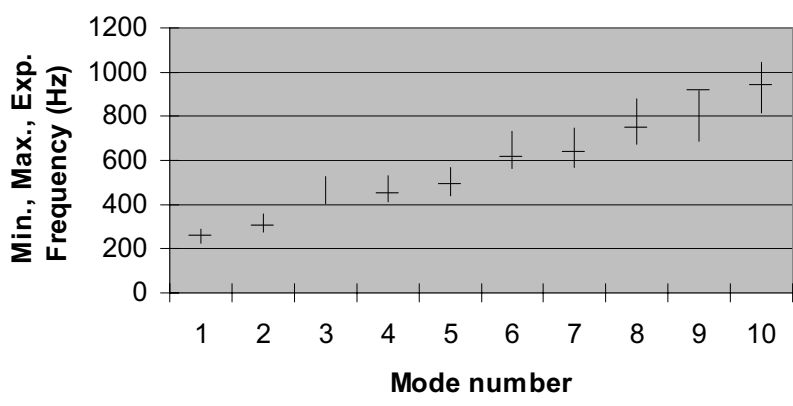

b) bearing support

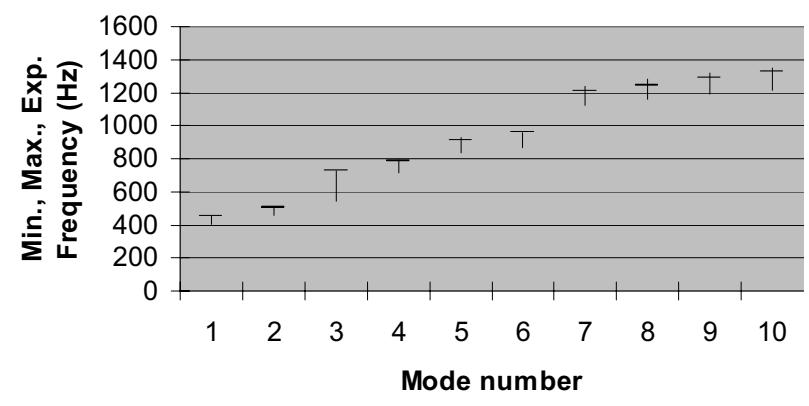

c) pump casing

Fig. 6. Numerical-experimental frequency correlation on free-free pump components.

For the pump casing, comparing the interval constituted by the minimum and maximal eigenfrequency values obtained by eight participants to the measured corresponding values (Fig. 6c), we can notice that every measured frequency is contained within the interval. The prediction accuracy on eigenfrequency values is less than $15 \%$ for the majority of modes considered; the numerical values are generally lower than experimental ones, that corresponds to a less stiff behaviour of the sub-structure. However, examining the $M A C$ numbers on the first four modes among the available results, the agreement between the mode shapes is not so clear [10]. The modes 1,2 and 4 are differently correlated regarding the participant; mode 3 shows the best agreement $(0.6<M A C<0.7)$.

These results are very satisfactory for this type of casting, whose external dimensions are not precisely known (typically the uncertainty on the casting shape between the pump casing and the exhaust pipe). Concerning the $M A C$ values, the measurement error of the geometry, which is complex, can be pointed out.

\subsubsection{Four-component system}

A numerical four-component system, composed of the bearing casing, the bearing support, the cooling flange and the pump casing, has been considered as an intermediate assembly before the complete pump assembly, in order to validate the representation of the connections. A two-component assembly without the shaft component would be a better built-up structure to do so, but experimental constraints did not permit to make such an assembly available.

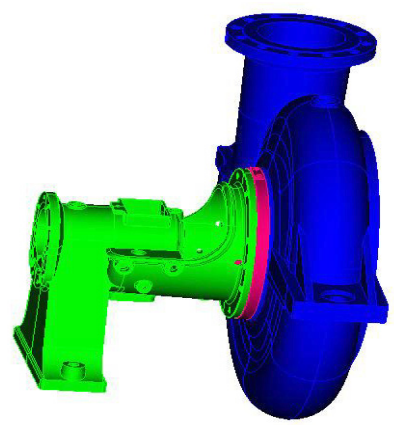

Fig. 7. Four pump component assembly: numerical CAD model.

Figure 7 presents the assembly of CAD models: the shaft is not represented, because the connection between this component and the other ones is light (simply supported in non rotating configuration) and is not very influential in the modal behaviour of the assembly. The bolted connections are simply taken into account using linear relationships in order to stick two component faces without representing the bolts. This rough representation can be justified by the high number of bolts which connect the pump components. The numerical-experimental correlation has been performed between the numerical fourcomponent system and the experimental five-component system (including the shaft).

The numerical-experimental correlation, illustrated on Figure 8, shows a rather good diagonal on the $M A C$ matrix for the seven first modes ( $M A C$ values between 0.27 and 0.88 ) and a $30 \%$ maximum frequency gap on the nine first modes. These satisfactory results, by suppressing the 
Table 5. Matching of blind first eigenmodes of the clamped pump assembly.

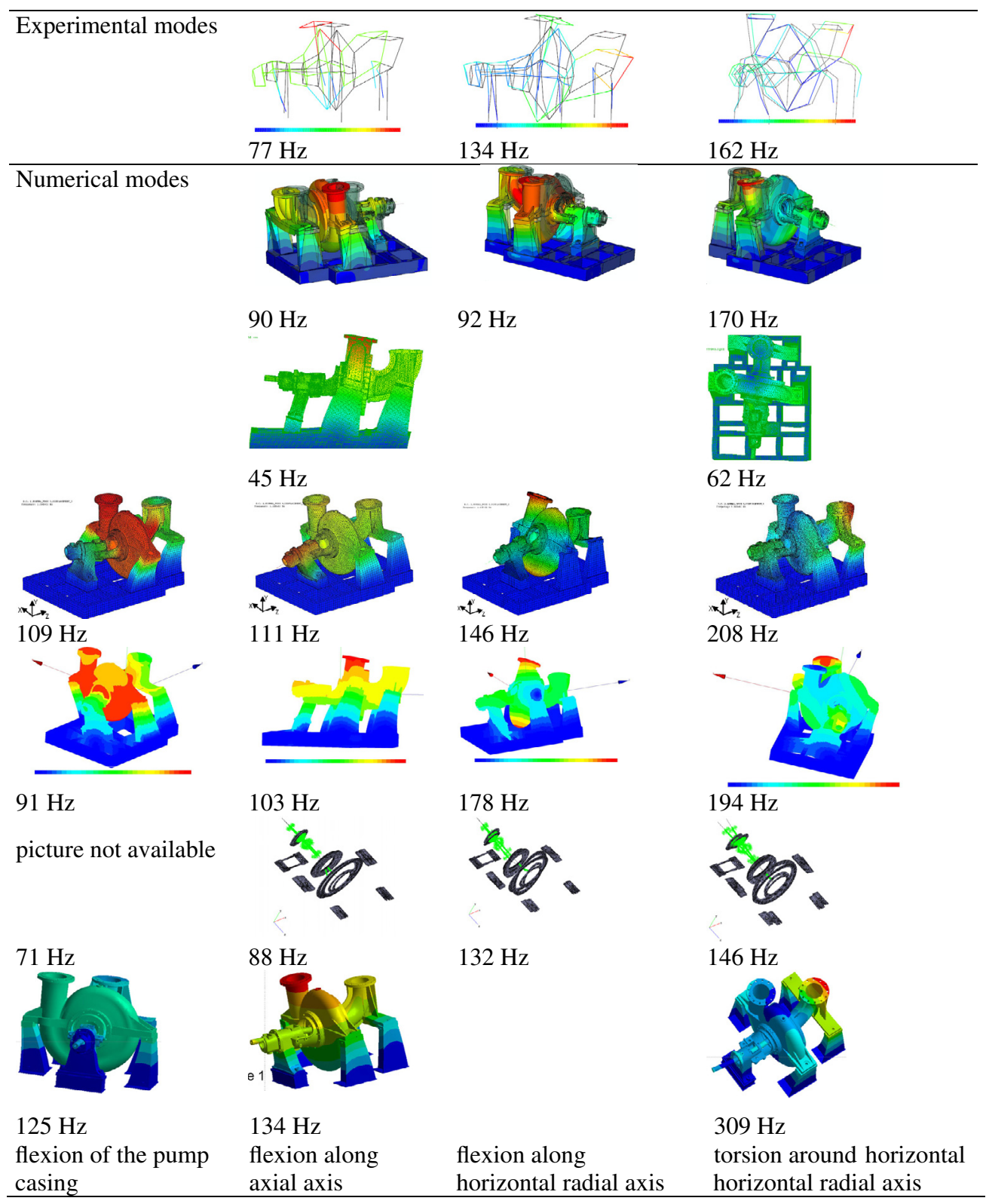

shaft, validate the sticked model of the bolted connections when the bolts are numerous.

\subsubsection{Non rotating pump assembly fixed in concrete}

Attempt has been made to qualitatively correlate the four first numerical and identified experimental eigenmodes (Tab. 5). One can notice that a numerical mode has been simulated by four partners among six, characterized by the flexion of the pump casing, which has no correspondent among identified experimental modes. The overall flexion along axial axis and torsion around horizontal radial axis has been numerically identified by all the partners. The overall flexion along horizontal radial axis could not be identified by two partners. Generally speaking, the eigenfrequency values present a high variability.

\subsection{Conclusion}

The variability of blind modal simulated predictions and the numerical-experimental correlation have been observed following a hierarchical process with more and more complexity in assembly and boundary condition: free pump components, an intermediate free 5-component system and the pump assembly with frame clamped in concrete have been successively considered. The satisfactory results obtained for the free pump components and the free 5-component system, in comparison with the large variability of eigenmodes observed for the clamped 


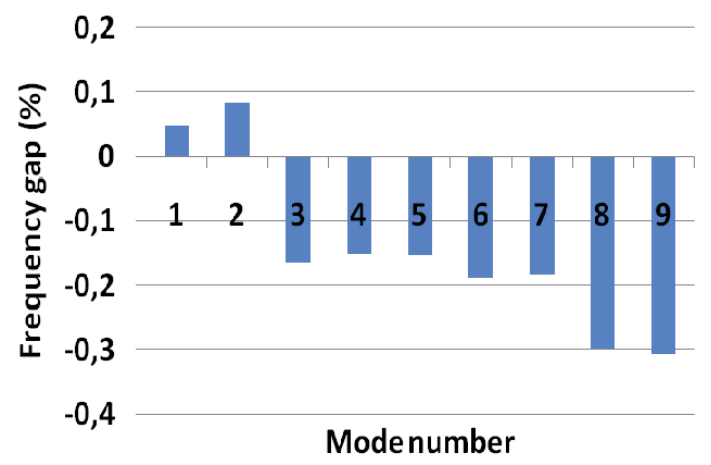

a) Numerical-experimental correlation on frequency values

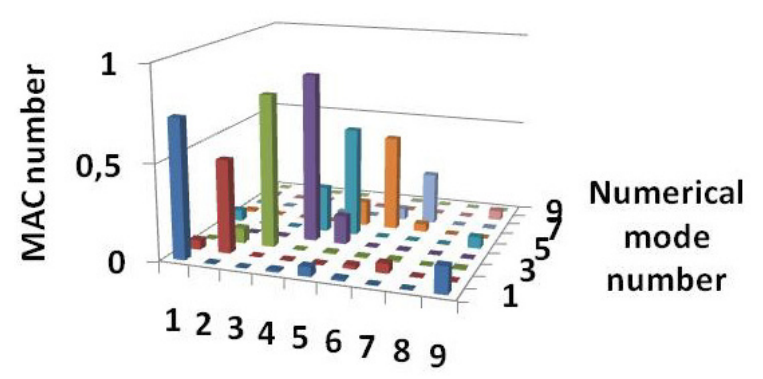

Experimental mode number

b) Numerical-experimental MAC matrix

Fig. 8. Numerical-experimental correlation on the 4-component system (9 first eigenmodes).

pump assembly, lead to focus our attention on the characteristics of the pump assembly: determination of equivalent material characteristics to take into account components non represented in the model and connection assumptions, and determination of stiffness joint values when joints are not numerous.

\section{Non rotating pump assembly model updating}

Two pump assembly models, with frame completely clamped, are hereafter considered by one partner; they are computed using Code_Aster Finite Element code [15].

The first one represents the bolted joints by rigid relationships and is used to update the material characteristics. The second one represents part of the bolted joints by discrete elements located on assembly interfaces between the frame and the three following components of the built-up pump: it is used to optimize stiffness characteristics of the discrete elements using a probabilistic analysis. A two-step procedure is so applied to elaborate the non rotating pump assembly model.

\subsection{Material characteristics}

A first attempt to update the pump assembly model consists in the variation of the main sensitive parameters: the material characteristics, that are the steel and cast iron Young's modulus and the density of the pump components, have been chosen. The five steel components are: pump casing, suction flange, elbow, frame and shaft \& impeller system. The three cast iron components are: bearing casing, bearing support and cooling flange.

\subsubsection{Young's modulus}

Considering that the numerical model is stiffer than it should be, in comparison with its experimental measurements, the Young's modulus of the two materials have to be reduced. This operation permits to take into account the nature (linear) of the meshes used and to make the model more flexible due to model assumptions which have been applied: sticking the jointed components, perfectly clamped boundary condition, choice of a cast iron Young's modulus mean value.

\subsubsection{Density}

The material density is a parameter of interest too, in order to take into account the lack of representation of some components (such as the internal components at the pump casing and the bearing support locations, the bolts) and the choice of non representation of the shaft due to the difficulty to model the shaft-bearing connection. Increasing the component density leads to a reduction of the pump assembly eigenfrequency values.

The reason why both the Young's modulus and the density are considered in the updating procedure, even though one parameter of the two would be enough, is justified by the objective of parameter values with physical meaning. Another way to reduce the pump assembly eigenfrequency values authorising but a limited variation of Young's modulus and density parameters would consist in getting the boundary condition more flexible considered stiffness springs instead of the clamped condition: the corresponding results, not presented here, showed a gradated numerical-experimental $M A C$ correlation matrix.

\subsubsection{Final parameter values after updating procedure}

Hereafter are the parameter values, obtained manually so that the numerical-experimental discrepancy on eigenfrequencies is minimized and the $M A C$ matrix optimized, in comparison with the initial values (Tab. 6). It can be remarked that material densities so determined are outside the usual range (from $7750 \mathrm{~kg} \cdot \mathrm{m}^{-3}$ to $8050 \mathrm{~kg} \cdot \mathrm{m}^{-3}$ for the steel and from $6800 \mathrm{~kg} . \mathrm{m}^{-3}$ to $7800 \mathrm{~kg} . \mathrm{m}^{-3}$ for the cast iron); this can be explained by the fact that those updated parameter values represent equivalent material characteristics which take into account missing pump components (only eight main pump components are modelled) and simplification of component geometries to reduce the final model size. 
Table 6. Initial and updated material characteristic values.

\begin{tabular}{ccccccc}
\hline & \multicolumn{2}{c}{ Initial } & & \multicolumn{2}{c}{ Updated } \\
\hline $\begin{array}{c}\text { Material } \\
\text { characteristics }\end{array}$ & Steel & Cast iron & & Steel & & Cast iron \\
\hline & & & Value & Variation & Value & Variation \\
\hline Young's modulus $(\mathrm{Pa})$ & $2.0 \times 10^{11}$ & $0.96 \times 10^{11}$ & $1.75 \times 10^{11}$ & $-12.5 \%$ & $1.0 \times 10^{11}$ & $+4.2 \%$ \\
\hline Density $\left(\mathrm{kg} . \mathrm{m}^{-3}\right)$ & 7800 & 7200 & 9360 & $+20.0 \%$ & 8640 & $+20.0 \%$ \\
\hline
\end{tabular}

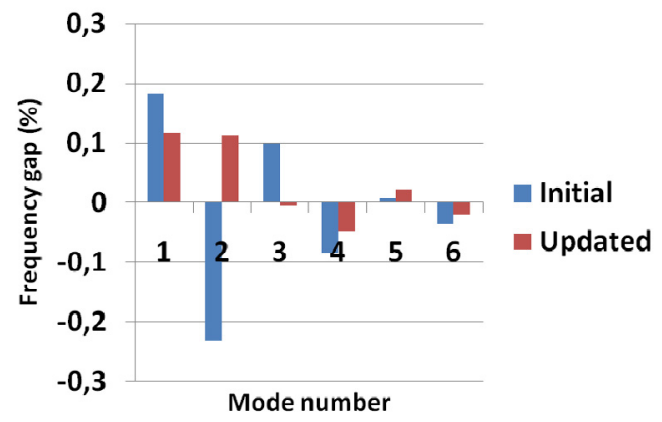

a) Numerical-experimental correlation on frequency values (left: initial value; right: updated value)

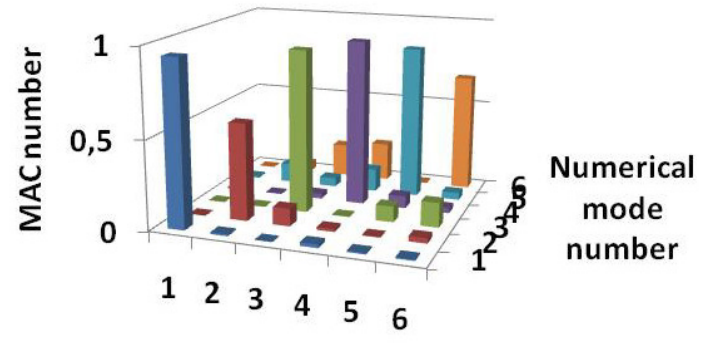

Experimental mode number

b) Numerical-experimental MAC matrix

Fig. 9. Numerical-experimental correlation of pump assembly after updating the material characteristics.

On Figure 9 is presented the result of the numericalexperimental correlation after the updating procedure of the pump assembly with frame completely clamped.

We observe a satisfactory correlation relatively to the 6 first eigenmodes. The $M A C$ values vary from 0.55 (mode 2) to 0.93 (modes 1,3 and 4); since the material characteristics applied are not different from component to component, the $M A C$ matrix is not influenced by the updating procedure. Attempt to vary the parameters component by component leads to less satisfactory correlation and so had not been retained. The discrepancy between numerical and experimentally identified eigenfrequencies is obviously improved: it is now about $10 \%$ relatively to the 6 first eigenmodes. One can nevertheless notice that the two first numerical eigenfrequency values are greater than the corresponding measured eigenfrequency values: considering the global proximity of the eigenfrequency values, we can assume a local less satisfactory representation model. Among the possible local phenomena that can affect the modal behavior of the pump assembly, we can incriminate the model of joint connection which specifically contains a low number of bolts (for instance the connection between the frame and the bearing support or the connection between the frame and the elbow) and for which the rigid relationship representation is not well adapted. A more precise model of these particular connections, where the connection area would be a parameter to tune, could improve the two first modes and control the rigidity of the whole pump assembly.

\subsection{Stiffness joints}

Here the bolted joints are represented by discrete elements located on assembly interfaces between the frame and the three following components of the built-up pump (Fig. 10): pump casing (joints 1 and 2), elbow (joints 3 and 4), and bearing casing (joints 5 and 6). This corresponds to two screws per pair of assembled components. Thus the flexibility of the assembly connections is characterized by the discrete stiffness given to the latter. In the following probabilistic analysis, the stiffness of the bolted joints are modeled as independent uniform random variables defined on intervals $\left[10^{5} ; 10^{9}\right] \mathrm{N} . \mathrm{m}^{-1}$. Other assembly interfaces of the pump (flange interfaces, ...) are modeled as fully constrained because they are constituted of a large number of screws [16].

From the statistical analysis of model output on a 400 size sample, a meta-model is built in order to reduce the computing time for the sensitivity analysis, useful for the parameter prioritization. Then the model parameter optimization process is performed on parameters which are selected consequently to the sensitivity analysis.

\subsubsection{Statistical analysis of model output}

Let us consider (3) the model output $\mathbf{Y}=$ $\left(Y_{1}, \ldots, Y_{8}\right)$ :

$$
\mathbf{Y}=f\left(X_{1}, X_{2}, \ldots X_{12}\right) \in R^{8}
$$

where $\mathbf{X}=\left(X_{1}, \ldots X_{12}\right) \in R^{12}$ is the vector of uncertain input parameters $\left(X_{i}, i=1, \ldots, 12\right.$ are the horizontal stiffness $\left(k_{x}, k_{y}\right)$ of the joints 1 to 6$)$. The variables of interest (model outputs) $Y_{i}, i=1, \ldots, 8$ for our study are eigenfrequencies FREQ and $M A C$ numbers with respect to the four experimental modeshapes.

Using a quasi Monte Carlo (MC) method and more precisely Sobol' sequences for design of numerical experiments $[17,18]$, we obtain the input sample 


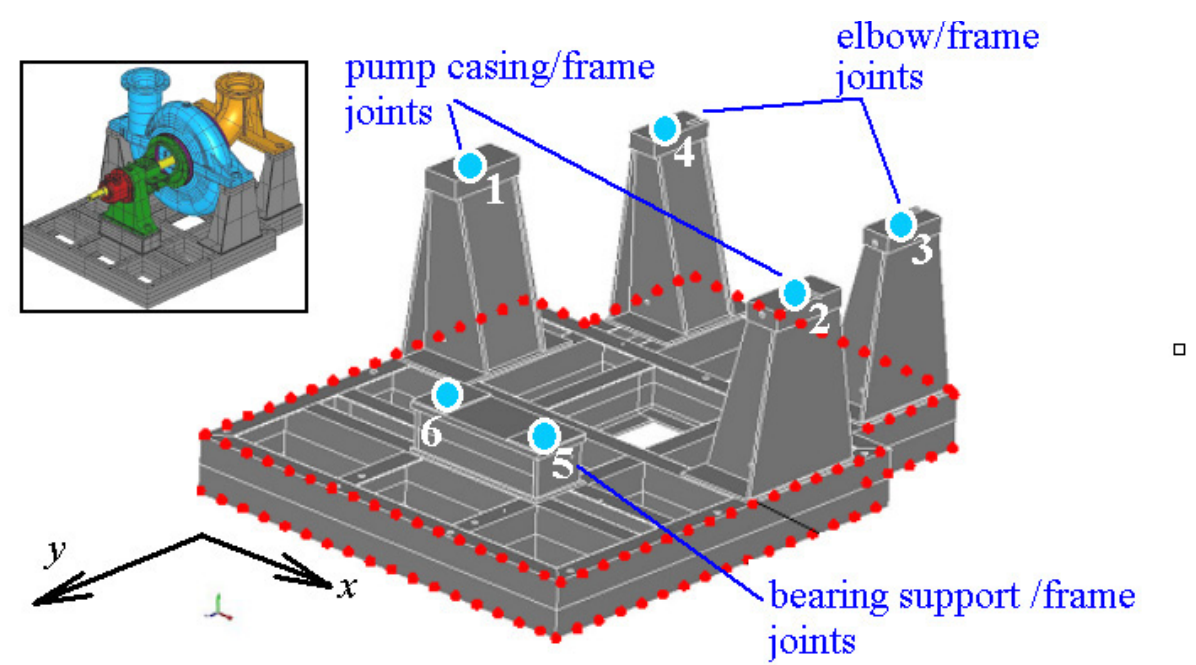

Fig. 10. Clamped zones of the frame and joint locations.

Table 7. Statistics of the four $M A C$ numbers and respective eigenfrequencies FREQ (sample size $\left.N_{\mathrm{s}}=400\right)$.

\begin{tabular}{lcccc}
\hline & Mean & Std & $C O V$ & $R$ \\
\hline$M A C 1$ & 0.936 & 0.002 & 0.00 & 0.58 \\
$F R E Q 1(\mathrm{~Hz})$ & 83.81 & 0.012 & 0.00 & \\
$M A C 2$ & 0.337 & 0.060 & 0.18 & 0.09 \\
$F R E Q 2(\mathrm{~Hz})$ & 141.23 & 2.537 & 0.02 & \\
$M A C 3$ & 0.679 & 0.065 & 0.10 & 0.33 \\
$F R E Q 3(\mathrm{~Hz})$ & 147.53 & 5.387 & 0.04 & \\
$M A C 4$ & 0.929 & 0.026 & 0.03 & 0.64 \\
$F R E Q 4(\mathrm{~Hz})$ & 192.87 & 2.291 & 0.01 & \\
\hline
\end{tabular}

$\mathbf{X}^{\mathrm{S}}=\left\{\mathbf{X}^{1}, \mathbf{X}^{2}, \ldots, \mathbf{X}^{N s}\right\}$ and the output sample $\mathbf{Y}^{\mathrm{S}}=$ $\left\{\mathbf{Y}^{1}, \mathbf{Y}^{2}, \ldots \mathbf{Y}^{N s}\right\}$ where $N_{\mathrm{s}}$ is the sample size, here $N_{s}=400$.

Generally speaking, the second and the third modes are very sensitive to the joint properties. The main results (mean, standard deviation, coefficient of variation $C O V$ and correlation coefficient $R$ between $M A C$ number and eigenfrequency) are reported in Table 7 . It can be seen that $M A C$ numbers are already (before optimization) very high for the modes 1 and 4: they are greater than 0.9 ; moreover their corresponding coefficients of variation are low, that indicates that the variation of the interface stiffnesses have a poor influence on them. The correlation coefficient between $M A C$ and frequency values is 0.64 at the maximum for mode 4 and is particularly low for mode 2 (0.09): this means that possible improvement of the numerical-experimental frequency gap after optimization will not systematically induce an improvement of corresponding $M A C$ values.

\subsubsection{Construction of the meta-model}

In order to be able to afford global sensitivity analysis and parameter identification, we construct a surrogate or meta-model $\hat{f}$ using kriging method; this yields (4) for each of the 8 outputs [19]:

$$
\hat{Y}_{i}=\hat{f}_{i}\left(X_{1}, X_{2}, \ldots X_{12}\right), \quad i=1, \ldots 8
$$

The accuracy of the surrogate has been assessed by means of cross-validation.

\subsubsection{Sensitivity analysis}

A preliminary global sensitivity analysis [16] using variance decomposition is performed in order to gain useful information for parameter priorisation [20-22]. The first order indices are defined by (5) [21]:

$$
S_{i}=\frac{\operatorname{Var}\left(E\left(Y / X_{i}\right)\right.}{\operatorname{Var}(Y)}
$$

The variables associated to the highest values of first order indices are supposed to be the best candidates to reduce variance of the model output. We have seen in Section 4.2.1 that variability of first and fourth eigenfrequencies and mode shapes is negligible; in consequence, sensitivity analysis results will be presented for the two other modes only (modes 2 and 3 ).

It can be showed in Figure 11 that the most influential model parameters are the stiffnesses of joints 5 and 6 in $x$ direction $\left(k_{x 5}\right.$ and $\left.k_{x 6}\right)$. Second most important parameters are the stiffnesses of joints 3 and 4 in $x$-direction $\left(k_{x 3}\right.$ and $\left.k_{x 4}\right)$.

\subsubsection{Model parameter optimization}

The optimal parameter values are determined by minimizing least-squared errors with respect to the experimental $M A C$ values:

$$
\mathbf{x}_{\mathrm{opt}}=\min _{\mathbf{X}} \sqrt{\sum_{i=1}^{4} w_{i}\left(1-\hat{f}_{i}^{M A C}(\mathbf{X})\right)^{2}}
$$


Table 8. Optimized stiffness joint parameters.

\begin{tabular}{lcccc}
\hline Joint number & 3 & 4 & 5 & 6 \\
\hline Horizontal stiffness in $x$ direction $k_{x}\left({\left.\mathrm{~N} . \mathrm{m}^{-1}\right)}^{7}\right.$ & $7.54 \times 10^{8}$ & $7.55 \times 10^{8}$ & $7.46 \times 10^{8}$ & $9.00 \times 10^{8}$ \\
\hline
\end{tabular}

Table 9. Numerical-experimental correlation before and after stiffness parameter optimization.

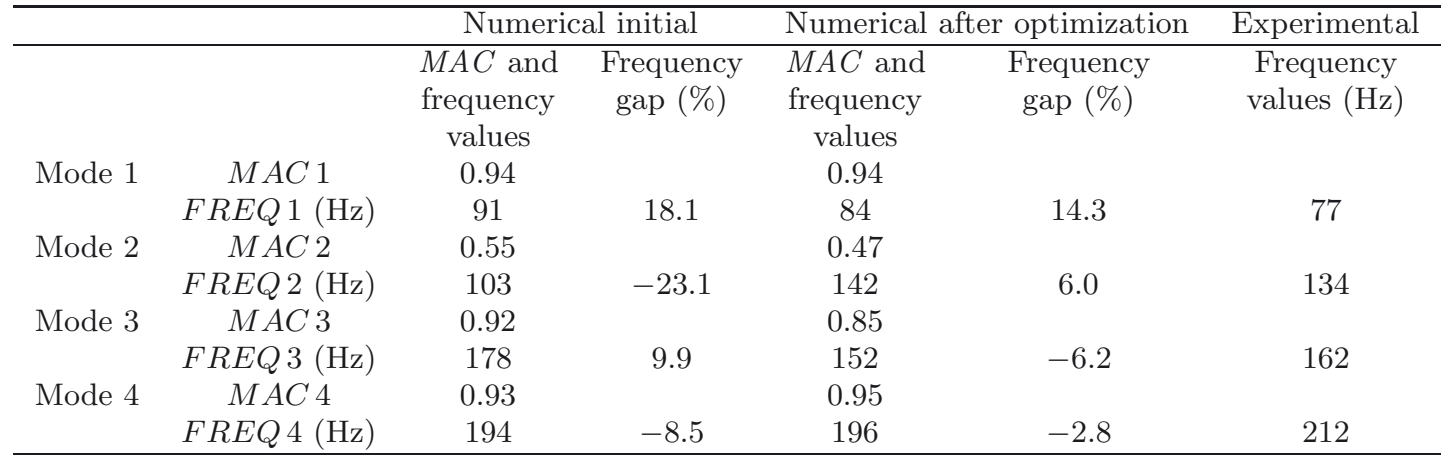

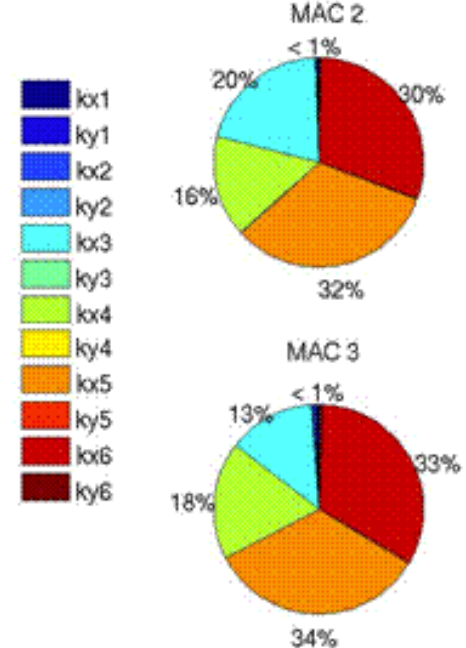

Fig. 11. Parameter ranking (first order sensitivity indices) for $M A C 2$ and $M A C 3$.

where $\hat{f}_{i}^{M A C}$ are the (meta-) model outputs concerning $M A C$ values. Consequently to the sensivity analysis results, the chosen weights $w_{i}$ are 0.4 for eigenmodes 2 and $3,0.2$ for eigenmode 4 , respectively. The $M A C$ value of the first eigenmode has been excluded from the optimization procedure $\left(w_{1}=0\right)$ since it does not vary as a function of the considered interface stiffnesses. The chosen weight for eigenmodes 2 and 3 is twice greater than the one for eigenmode 4 because their corresponding coefficients of variation ( 0.18 and 0.10 respectively) are significantly higher than the coefficient of variation 0.01 for mode 4: a more efficient optimization can be so obtained in acting predominantly on their values. The optimized $M A C$ values along with the respective eigenfrequencies are given in Table 9. The corresponding parameter set is given in Table 8.

It is observed that the properties of the bolted joints modeled using discrete elements do not allow improving the $M A C$ numbers of the second and third mode: the values are even so a bit lower than the initial ones. However the numerical-experimental frequency gap is largely improved, so that the optimized numerical model so obtained is quite satisfactory.

\subsection{Updating conclusions}

The two-step updating procedure, first involved with material characteristics and second with stiffness joints, leads to a numerical-experimental correlation characterized by a $9 \%$ maximal frequency discrepancy and a $M A C$ number generally greater than 0.9 on the four first eigenmodes. If we consider the experimental reference data used as perfect, improvement could certainly be reached by studying a more precise representation of the boundary condition, perhaps partially clamped instead of completely clamped. Nevertheless one must keep in mind the experimental variability and consider that the reference data here considered for numerical-experimental correlation purpose are relative to one specimen of nominally identical structures. Furthermore the quality of the concrete is varying with time, leading to a time variation of the pump assembly eigenmodes, as a consequence of the modification of the clamped boundary condition.

Approaching methods to represent and update bolted joints, and estimate the joint behavior variability can be found in the literature. In reference [23] is developed a one-dimensional linear joint model which is capable of representing the behavior of every joint of a large structure globally; an efficient updating algorithm is then proposed for this model which could be easily extended to very complex structures. The bolted joint behavior variability is estimated using the Lack of Knowledge theory in reference [24].

\section{The 2012-2015 FUI SICODYN project}

The 2008-2010 SICODYN benchmark results, based on an industrial structure and gathering both industrial 


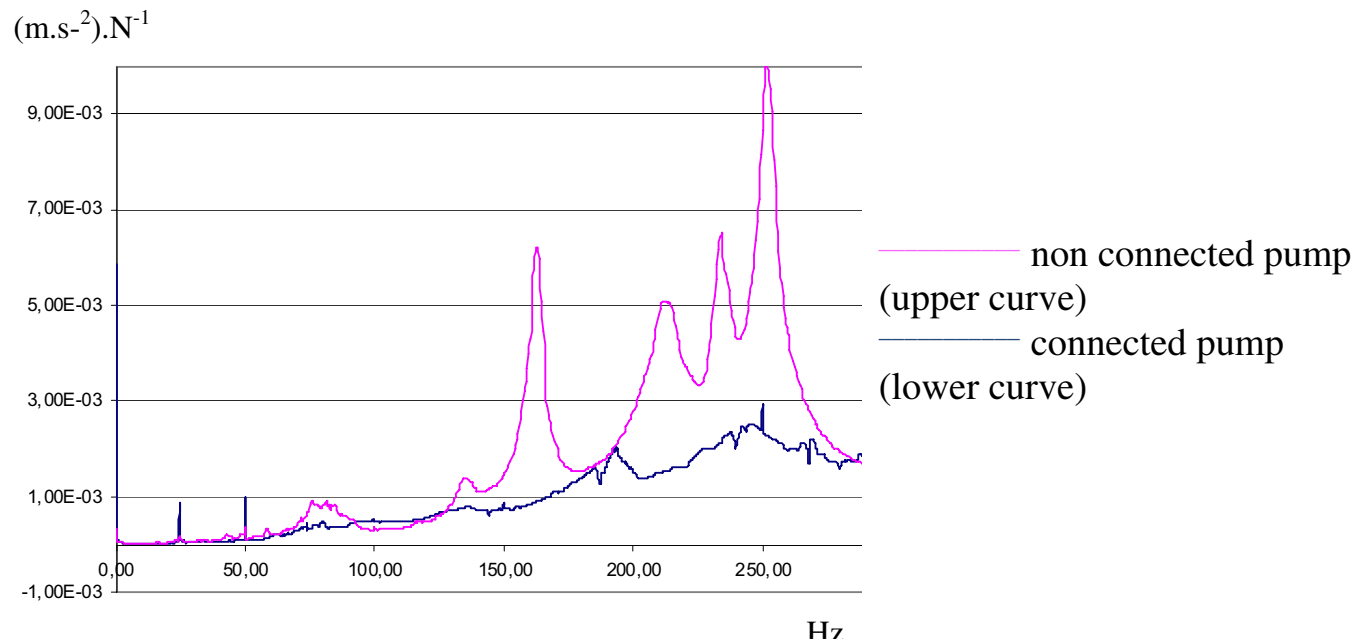

Fig. 12. Frequency response of the pump assembly to a hammer excitation.

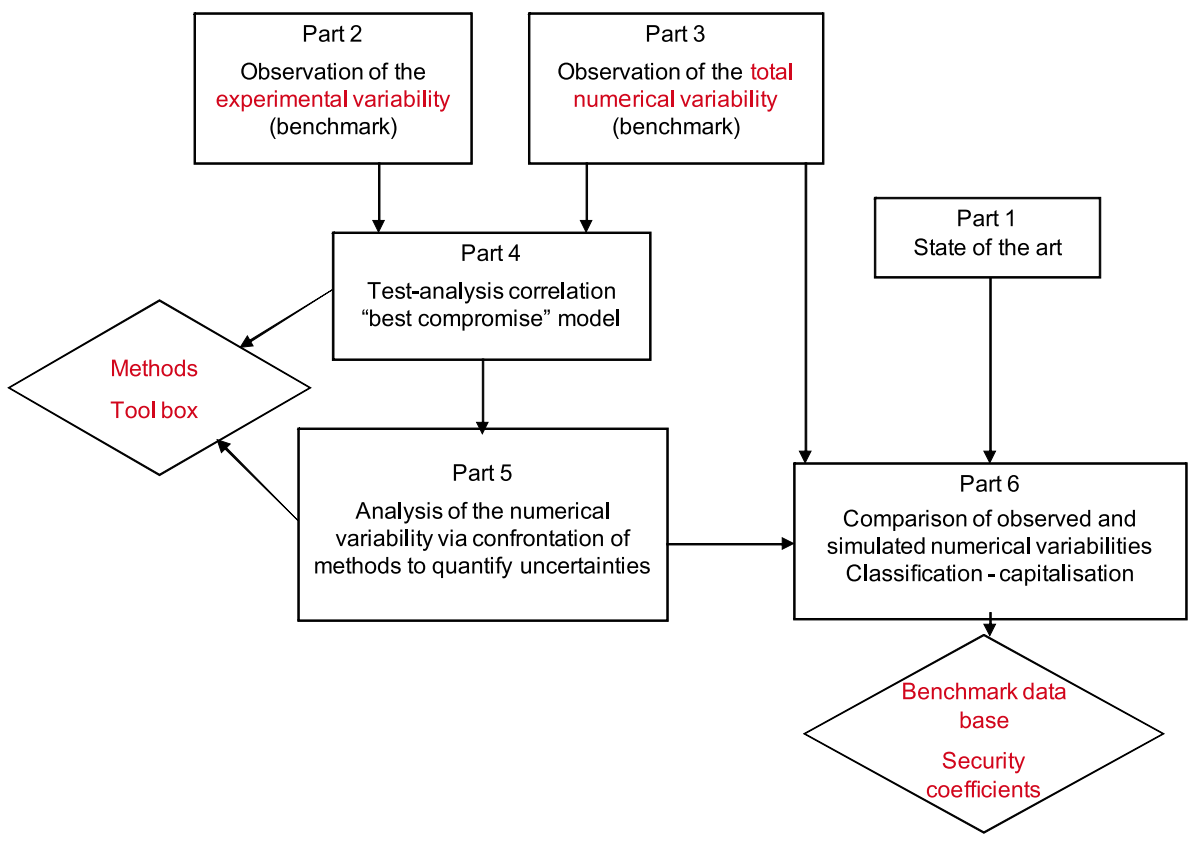

Fig. 13. Organization of the six parts of the SICODYN project.

companies and universities, brought the opportunity to go on further and propose a more ambitious research program. This program was accepted as a financed FUI project, untitled SICODYN (pour des SImulations crédibles via la COrrélation calculs-essais et l'estimation d'incertitudes en DYNamique des structures). The demonstrator is still the booster pump, but the boundary conditions are more complex, in order to take into account the real industrial environment: in addition of the frame clamped in concrete, the pump is connected to pipes. Figure 12 well illustrates the difficulty so induced: the frequency response to a hammer excitation of the pump permits an easy extraction of the eigenmodes in case of the non connected pump; on the opposite, when the pump is connected, the determination of the peaks objectively presents more difficulty.
The idea underlying the project is to give easy tools, based on tested methodologies, to a priori estimate the confidence associated to a dynamical simulation-based prediction [25-29]. The general organisation of the six parts of the project is described in Figure 13. In Part 1, an inventory of the benchmarks in structure dynamics and a review of methods which estimate the total uncertainty (model parameter uncertainty plus model form uncertainty) will be made. Two benchmarks (Parts 2 and 3) will permit to observe the total numerical variability, as in the previous SICODYN benchmark, and the experimental variability, related to nominally-identical structures [30], or different operators. Part 4 will be devoted to test-analysis correlation, using notably a collection of numerical results and a collection of experimental measurements [31]. In Part 5, both parametric and non parametric 
methods will be confronted in order to quantify the uncertainties, either in a deterministic (method of intervals...) or probabilistic context [32-37].

In Part 6, the observed (via the benchmark) and simulated (in Part 5) numerical variabilities will be compared. The most appropriate methods, from an industrial point of view, will be retained and possibly derived in simple security coefficients and margins applied in classes of dynamical problems to determine.

\section{Conclusion}

A main objective of the work here presented is to quantify the confidence in numerical models used either in design purpose or in expertise purpose and finally to ensure robust predictions, that is with a difference between prediction and actual response which is within an acceptable range including all uncertainties. In order to measure the effective variability on structural dynamics computations we can observe among different operators and in comparison with reference experimentally measured data, an international benchmark is organized, based on an industrial demonstrator well-representative of modeling complexity and with not well-known parameters. That built-up dynamical system is a pump actually in service in power plants, considered in its work environment.

The blind modal variability is studied following a hierarchical process which considers more and more complexity in assembly and boundary condition of the separate pump components. The separate free-free pump components show a $12 \%$ maximal variability on eigenfrequency values, which authorises the use of the characterisation of their dynamical behaviour; on the contrary, the observed variability of blind results on the clamped pump assembly is so larger that it can be considered that the modal characterisation of the structure is not confident. This is essentially due to possible simplifying process in order to reduce the model final size, assembling procedure at a macro level, applying kinematics relationships or considering fully restrained connections and modelling boundary conditions.

Concerning the numerical-experimental correlation, it can be said that, generally speaking, the more the substructures, the more the numerical-experimental discrepancy increases. Experimental-numerical correlation had been performed for three separate pump components, a five-component system and the clamped pump assembly: for the nine first modes considered, if the frequency error is less than $15 \%$ for the free sub-structures, it reaches $30 \%$ for the free 5-component system and, though the first overall modes are correctly identified, can be significantly larger for the clamped pump assembly. On the contrary, the numerical-experimental $M A C$ numbers are not lower for the pump assembly; they can be higher than 0.9 for two modes. A two-step updating procedure of the clamped pump assembly permits to improve the model representation so that the eigenfrequency discrepancy is less than $9 \%$ for the four first modes.
A lesson to draw is that the quality of theoretical builtup structure models lags far behind the quality achieved in conventional structure components, due to the lack of appropriate models of the interfaces and joints, easily usable in case of real industrial degree of complexity; nevertheless, their representation can be largely improved using experimental information. Furthermore it must be kept in mind that the variability concept must be enlarged in view of the use of numerical models for a whole family of nominally-identical structures and considering numerical and experimental uncertainties.

After this benchmark, a more ambitious research program will follow as a FUI project. The idea underlying the project is to give easy tools, based on tested methodologies, to a priori estimate the confidence associated to a dynamical simulation-based prediction. It is based on several parts concerned with a numerical benchmark of the same pump assembly in more complex environmental conditions, an experimental benchmark on this same structure in order to quantify the measurement uncertainty, the improvement of the numerical-experimental correlation, a comparative quantification of the total uncertainty (parameter and model uncertainties) using probabilistic and non probabilistic methods, and the elaboration of user-friendly methods to a priori determine the confidence of a given type of a structure dynamics simulation. The challenge of this comprehensive approach is testing the capability of methods to predict uncertainties to reproduce the variability observed within the benchmark.

Acknowledgements. The authors would like to acknowledge all the participating groups, and the support of SULZER Pompes France for making the booster pump data available and for authorising EDF R\&D to carry out vibration test measurements on it.

\section{Appendix 1: participating groups}

The 11 partners currently involved in 2008-2010 SICODYN benchmark are:

- Institut FEMTO-ST UMR CNRS 6174: E. Foltête, M. Ouisse.

- LAMCOS UMR CNRS 5259 INSA Lyon: S. Baguet, R. Dufour, C. Duran.

- ViBRATEC: C. Clerc, A. Coulon, C. Devemy.

- CETIM: Y. Goth, J. Peigney.

- PHIMECA Engineering: E. Noret, T. Yalamas.

- SAMTECH: P. Pasquet.

- (SUlZER Pompes France) $)^{1}$ : R. Petit, P. Courcot.

- EDF R\&D: S. Audebert, C. Bodel, P. Cadou, A. Mikchevitch, I. Lakhssassi.

- Delft University of Technology (TU Delft, the Netherlands): D. Rixen, E. Hooijkamp.

1 SULZER Pompes France is not involved in performing simulations, but in facilitating any work in relation with the structure itself (pump characterisation, experimental aspects, informations needed to simulate its dynamical behaviour) 
- MSO Industrial (Colombia): N. Rueda.

- CAEnable (USA): K. Sivagnanam.

The 13 partners currently involved in 2012-2015 SICODYN project are:

- ASTRIUM Space Transportation: B. Troclet, D . Clerc, S. Muller, H. Baumont.

- CETIM: Y. Goth.

- EDF R\&D: S. Audebert, A. Mikchevitch.

- LMT ENS Cachan: F. Louf, L. Champaney, O. Dorival, S. Daouk.

- Institut FEMTO-ST UMR CNRS 6174: M. Ouisse, S. Cogan, E. Foltête, J.L. Raynaud, T. Weisser.

- LAMCOS UMR CNRS 5259 INSA Lyon: B. Faverjon, G. Jacquet-Richardet, M.A. Randrianoely, M.A. Douville.

- MSME UMR-CNRS 8208: A. Batou, C. Soize.

- NECS Numerical Engineering and Consulting Service: S. Ghavamian, L. Dall'Ollio.

- PHIMECA Engineering: T. Yalamas, K. Macocco, P. Willaume.

- LMS-SAMTECH: P. Barabinot, C. Kaici.

- SOPEMEA: T. Becher, Y. Courtay, P. Birr.

- SULZER Pompes France: F. Muzard, R. Petit.

- VIBRATEC: C. Clerc, A. Coulon.

\section{References}

[1] T.G. Trucano, L.P. Swiler, T. Igusa, W.L. Oberkampf, M. Pilch, Calibration, validation, and sensitivity analysis: What's what, Reliab. Eng. Syst. Saf. 91 (2006) 1331-1357

[2] W.L. Oberkampf, T.G. Trucano, Verification and validation benchmarks, Nucl. Eng. Design 238 (2008) 716-743

[3] C. Zang, C.W. Schwingshackl, D.J. Ewins, Model validation for structural dynamic analysis: An approach to the Sandia Structural Dynamic Challenge, Comput. Methods Appl. Mech. Engrg. 197 (2008) 2645-2659

[4] R.G. Hills, M. Pilch, K.J. Dowding, J. Red-Horse, T.L. Paez, I. Babuska, R. Tempone, Validation Challenge Workshop, Comput. Methods Appl. Mech. Engrg. 197 (2008) 2375-2380

[5] T.L Paez, J. Red-Horse, Structural dynamics challenge problem: Summary, Comput. Methods Appl. Mech. Engrg. 197 (2008) 2660-2665

[6] J. Red-Horse, T.L Pae, Sandia National Laboratories Validation workshop: Structural dynamics application, Comput. Methods Appl. Mech. Engrg. 197 (2008) 2578-2584

[7] M. Link, M. Friswell, Working group 1: generation of validated structural dynamic models - Results of a benchmark study utilising the GARTEUR SM-AG19 test-bed, Mech. Syst. Signal Process. 17 (2003) 9-20

[8] S. Atamturkur, F.M. Hemez, J.A. Laman, Uncertainty quantification in model verification and validation as applied to large scale historic masonry monuments, Eng. Struct. 43 (2012) 221-234

[9] M.H. de A. Carqueja, J.D. Riera, Model uncertainty in the determination of dynamic response of generator foundation, in: Michel Livolant; The
International Association for Structural Mechanics in Reactor Technology (IASMIRT) (eds.), Transactions of the 14th International Conference on Structural Mechanics on Reactor technology SMiRT14 (1997), Lyon, France, 1997, pp. 95-102

[10] S. Audebert, SICODYN International benchmark on dynamic analysis of structure assemblies: variability and numerical-experimental correlation on an industrial pump, Mécanique et Industries 11 (2010) 439-451

[11] Jeong Kim, Joo-Cheol Yoon, Beom-Soo Kang, Finite element analysis and modeling of structure with bolted joints, Appl. Math. Modell. 31 (2007) 895-911

[12] J. Mackerle, Finite element analysis of fastening and joining: a bibliography (1990-2002), Int. J. Press. Vessels Piping 80 (2003) 253-271

[13] D. Dane Quinn, Modal analysis of joined structures, J. Sound Vib. 331 (2012) 81-93

[14] A. Gallina, W. Lisowski, L. Pichler, A. Strachowski, T. Uhl, Analysis of natural frequency variability of a brake component, Mech. Syst. Signal Process. 32 (2012) 188-199

[15] Code_Aster, general public licensed structural mechanics finite element software, http://www. code-aster.org/

[16] S. Audebert, I. Zentner, A. Mikchevitch, Variability and propagation of uncertainties on modal simulations of a built-up structure (SICODYN benchmark), in: G. de Roeck, G. Degrande, G. Lombaert, G. Müller (eds.), Proceedings of the 8th International Conference on Structural Dynamics, ISBN 978-90-760-1931-4, EURODYN 2011, Leuwen, Belgium, 2011, pp. 3000-3007

[17] Sacks et al., Design and analysis of computer experiments, Stat. Sci. 4 (1989) 409-423

[18] I. M. Sobol', V.I. Turchaninov, Y. L. Levitan, B.V. Shukhman, Quasirandom sequence generators, Ipm zak. no. 30, Keldysh Institute of Applied Mathematics, Russian Academy of Sciences, Moscow, 1992

[19] DACE. A Matlab Kriging Toolbox. S. Lophaven et al., Technical report IMM-TR-2002-12, 2002

[20] E. de Rocquigny, N. Devictor, S. Tarantola, Uncertainty in industrial practice. A guide to quantitative uncertainty management, Wiley \& Sons eds. Chichester, England, 2008

[21] I. Zentner, S. Tarantola, E. de Rocquigny, Sensitivity analysis for reliable design verification of nuclear turbosets, Reliab. Eng. Syst. Saf. 96 (2010) 391-397

[22] A. Saltelli, M. Ratto, T. Andres, E. Campolongo, J. Cariboni, D. Gatelli, M. Saisana, S. Tarantola, Global sensitivity analysis, The primer, Wiley, 2008

[23] F. Gant, P. Rouch, F. Louf, L. Champaney, Definition and updating of simplified models of joint stiffness, Int. J. Solids Struct. 48 (2011) 775-784

[24] F. Gant, L. Champaney, P. Rouch, Modeling of the bolted joint behavior variability with the Lack of Knowledge theory, in: ICCES Organizing Committee, Tech. Science Press (ed.), ISSN:1933-2815, ICCES 2010 International Conference on Computational and Experimental Engineering and Sciences, Las Vegas, USA, 2010, vol. 14, pp. 97-98

[25] C.J. Roy, W.L. Oberkampf, A comprehensive framework for verification, validation, and uncertainty quantification in scientific computing, Comput. Methods Appl. Mech. Engrg. 200 (2011) 2131-2144 
[26] C. Unal, B. Williams, F. Hemez, S.H. Atamturktur, P. Mc Clure, Improved best estimate plus uncertainty methodology, including advanced validation concepts, to licence evolving nuclear reactors, Nucl. Eng. Design 241 (2011) $1813-1833$

[27] S. Atamturktur, F. Hemez, B. Williams, C. Tome, C. Unal, A forecasting metric for predictive modelling, Comput. Struct. 89 (2011) 2377-2387

[28] J.R. Langenbrunner, F.M. Hemez, J.M. Booker, T.J. Ross, Model choice considerations and information integration using analytical hierarchy process, Sixth International Conference on Sensitivity Analysis of Model Output, Procedia Social and Behavioral Sciences 2 (2010) 7700-7701

[29] M. Pilch, T.G. Trucano, J.C. Helton, Ideas underlying the quantification of margins and uncertainties, Reliab. Eng. Syst. Saf. 96 (2011) 965-975

[30] A. Batou, C. Soize, M. Corus, Experimental identification of an uncertain computational dynamical model representing a family of structures, Comput. Struct. 89 (2011) 1440-1448

[31] W.L. Oberkampf, M.F. Barone, Measures of agreement between computation and experiment: validation metrics, J. Comput. Phys. 217 (2006) 5-36
[32] B. Van den Nieuwenhof, J.P. Coyette, Modal approaches for the stochastic finite element analysis of structures with material and geometry uncertainties, Comput. Methods Appl. Mech. Engrg. 192 (2003) 3705-3729

[33] D.C. Kammer, S. Nimityongskul, Propagation of uncertainty in test-analysis correlation of substructured spacecraft, J. Sound Vib. 330 (2011) 1211-1224

[34] M. Guedri, S. Cogan, N. Bouhaddi, Robustness of structural reliability analyses to epistemic uncertainties, Mech. Syst. Signal Process. 28 (2012) 458-469

[35] A.K. Der Kiureghian, O. Ditlevsen, Aleatory or epistemic? Does it matter? Struct. Safe. 31 (2009) 105-111

[36] L. Hinke, Modelling approaches for the low-frequency analysis of built-up structures with non-deterministic properties, Master Thesis, University of Southampton, Faculty of Engineering, Science and Mathematics, Institute of Sound and Vibration Research, 2008

[37] B.R. Mace, P.J. Shorter, A local modal perturbational method for estimating frequency response statistics of built-up structures with uncertain properties, J. Sound Vib. 242 (2001) 793-811 